\title{
Comparison of pancreatic function and quality of life between patients with infected pancreatitis necrosis undergoing open necrosectomy and minimally invasive drainage: A long-term study
}

\author{
JIANFENG TU ${ }^{1-4 *}$, JINGZHU ZHANG $^{1 *}$, YUE YANG $^{3 *}$, QIURAN XU ${ }^{2}$, \\ $\mathrm{LU} \mathrm{KE}^{1}$, ZHIHUI TONG ${ }^{1}$, WEIQIN $\mathrm{LI}^{1}$ and JIESHOU LI ${ }^{1}$
}

\begin{abstract}
${ }^{1}$ Research Institute of General Surgery, Jinling Hospital, Medical School of Nanjing University, Nanjing, Jiangsu 210002;
${ }^{2}$ Department of Emergency Medicine, Zhejiang Provincial People's Hospital, People's Hospital of Hangzhou Medical College, Hangzhou, Zhejiang 310014; ${ }^{3}$ Institute of Innovation and Entrepreneurship, Hangzhou Medical College, Hangzhou, Zhejiang 310053; ${ }^{4}$ Department of General Surgery, Akesu First People's Hospital, Akesu, Xinjiang 843000, P.R. China
\end{abstract}

Received September 2, 2019; Accepted March 10, 2020

DOI: $10.3892 / \mathrm{etm} .2020 .9203$

\begin{abstract}
The present study aimed to determine whether a difference in pancreatic function and quality of life (QoL) is present between patients with infected pancreatitis necrosis (IPN) undergoing open necrosectomy (ON) and minimally invasive drainage (MID). The medical records of patients with IPN discharged from Jinling Hospital were retrospectively analyzed. Pancreatic function and QoL were compared between patients treated with ON and MID. Pancreatic endocrine and exocrine function were assessed using the oral glucose tolerance test and fecal elastase-1 (FE-1) test, respectively. The standard Short Form 36 health questionnaire was used to evaluate the QoL of patients. The analysis included 101 patients who underwent either ON ( $n=40,39.6 \%)$ or MID $(n=61,60.4 \%)$. There were no significant differences in exocrine and endocrine pancreatic function between the two groups evaluated based on FE-1, fasting blood glucose, glycated hemoglobin and 2-h plasma glucose $(\mathrm{P}<0.05)$. The scores of the QoL questionnaire were significantly higher in patients treated with MID than in patients treated with ON, including the scores of general health perception $(19.39 \pm 3.07$ vs. $17.37 \pm 3.63$, $\mathrm{P}=0.003)$, vitality $(18.93 \pm 2.88$ vs. $17.57 \pm 3.47, \mathrm{P}=0.035)$, social role functioning $(8.85 \pm 1.43$ vs. $8.15 \pm 1.98, \mathrm{P}=0.042)$, emotional role functioning $(5.33 \pm 1.07$ vs. $4.82 \pm 1.25, \mathrm{P}=0.034)$, mental health $(24.21 \pm 3.31$ vs. $22.57 \pm 3.91, \mathrm{P}=0.026)$ and the total $\mathrm{QoL}$
\end{abstract}

Correspondence to: Professor Weiqin Li or Dr Zhihui Tong, Research Institute of General Surgery, Jinling Hospital, Medical School of Nanjing University, 305 East Zhongshan Road, Nanjing, Jiangsu 210002, P.R. China

E-mail: njzy_pancrea@163.com

E-mail: njzyantol@hotmail.com

*Contributed equally

Key words: infected pancreatitis necrosis, open necrosectomy, minimally invasive drainage, pancreatic function, quality of life score $(125.12 \pm 13.16$ vs. $116.50 \pm 16.94, \mathrm{P}=0.005)$. In conclusion, although the initial health of the patient may have influenced the treatment provided, patients with IPN who received MID achieved a better post-treatment QoL than those treated with ON. No significant differences between the two groups were observed regarding the endocrine and exocrine functions of the pancreas.

\section{Introduction}

An estimated $15-20 \%$ of patients with acute pancreatitis (AP) develop necrosis of pancreatic parenchyma and/or peripancreatic necrosis $(1,2)$. Pancreatic necrosis is associated with a mortality rate ranging from 8 to $30 \%$ (3). Infected pancreatitis necrosis (IPN) is typically treated by minimally invasive drainage (MID) or open necrosectomy (ON) $(2,3)$. Most studies have demonstrated that $\mathrm{ON}$ is associated with high morbidity and mortality (4-11). MID was indicated to decrease mortality without increasing the complications of the infection of infection-associated mortality (12-14). However, to the best of our knowledge, the long-term follow-up of pancreatic endocrine and exocrine function and quality of life (QoL) of patients with IPN has not previously been performed and the difference of pancreatic function and QoL between patients undergoing ON and MID is unknown.

Damaged pancreatic acinar cells may recover after interstitial edematous pancreatitis, improving pancreatic function (15), and complete recovery of pancreatic acinar cells has been documented (16). However, a considerable proportion of patients who recovered from IPN have an impaired endocrine and exocrine pancreatic function (17). Thus, the objective of the present study was to determine the long-term outcomes of patients with IPN treated with ON or MID in terms of pancreatic function and QoL.

\section{Patients and methods}

General information. Patients with IPN who received MID or ON between January 2000 and February 2015 at Jinling 
Hospital, Medical School of Nanjing University (Nanjing, China), were included in the present study. The patients were divided into the MID and ON groups based on the interventional approach they received. Demographic data, time spent in the intensive care unit (ICU), the CT severity index (CTSI), Acute Physiology and Chronic Health Evaluation (APACHE) II score and body mass index (BMI) were retrieved from medical records. For all patients, the evaluation of pancreatic endocrine and exocrine function and QoL was performed in May 2016. Written informed consent was obtained from each patient. The protocol of the present study was approved by the ethics committee of Jinling Hospital, Medical School of Nanjing University (Nanjing, China).

The area of pancreatic necrosis was assessed by experienced radiologists based on the necrotic features in the contrast-enhanced CT (CECT) images. IPN was diagnosed on the basis of a positive culture of pancreatic or peripancreatic necrotic tissue obtained from the first drainage procedure or operation or the presence of gas in the fluid collected during CECT.

MID consisted of a sequence of three procedures (18): Percutaneous catheter drainage (PCD), negative pressure irrigation (NPI) and endoscopic necrosectomy (ED) via an artificial sinus tract. Image-guided PCD was considered the first choice for intervention. For this procedure, pigtail tubes were placed using a CT- or ultrasound-guided Seldinger puncture technique in the area of pancreatic necrosis via the retroperitoneum or peritoneum, depending on the location of IPN and adjacent organs (10). NPI was performed using a 'double catheterization cannula' to ensure continuous irrigation of the cavity. ED was performed using a $30 \mathrm{~F}$ electronic gastroscope inserted through the sinus tract created by double catheterization cannulas and a snare was used to extract out a large volume of necrotic tissue that was difficult to be removed by NPI and PCD.

ON consisted of two steps: First, a laparotomy was performed through bilateral subcostal incisions for blunt removal of the necrotic tissue, and double catheterization cannulas or drainage tubes were then placed for post-operative lavage. The decision to perform ON or MID was made by multidisciplinary discussion between surgeons, internist physician and radiologists, taking into account the area and location of necrosis, abdominal pressure, vital signs and the patient's preference.

Exclusion criteria. The exclusion criteria were as follows: i) Chronic pancreatitis; ii) diagnosis of diabetes mellitus (DM) prior to the IPN episode; iii) chronic diarrhea prior to IPN; iv) intestinal tuberculosis or Crohn's disease; v) family history of DM; vi) incomplete medical records; vii) death during hospitalization or after discharge from hospital; viii) conditions influencing QoL after discharge, including mental diseases, immune system diseases and malignant tumors.

Assessment methods and data collection. Simplified oral glucose tolerance test (19) and fecal elastase-1 (FE-1) test (BIOSERV Diagnostics $\mathrm{GmbH}$ ) were used to evaluate the pancreatic endocrine and exocrine function, respectively. The data on fasting blood glucose (FBG), free insulin (FINS), fasting C-reactive-peptide, glycated hemoglobin (HbA1c), 2-h plasma glucose (PG), 2-h C-reactive peptide and 2-h insulin, were also collected.

Stool samples were collected for the FE-1 test and stored at $-20^{\circ} \mathrm{C}$. Concentrations of FE-1 in the stool were interpreted as follows: $>200 \mu \mathrm{g} / \mathrm{g}$ stool, normal exocrine pancreatic function; $100-200 \mu \mathrm{g} / \mathrm{g}$ stool, mild to moderate exocrine pancreatic function; $<100 \mu \mathrm{g} / \mathrm{g}$ stool, severe exocrine pancreatic dysfunction $(20,21)$.

CT images were used to determine the loss of pancreas of the patients discharged from hospital. The incidence of $100 \%$ loss of the pancreas was compared between the MID and ON groups.

The standard short form (SF)-36 questionnaire (22) was used to assess the QoL of patients. SF-36 consists of 8 sections designed to evaluate 8 domains of health, including physical functioning, physical role functioning, bodily pain, general health perceptions, vitality, social role functioning, emotional role functioning and mental health. Patients completed the questionnaire by themselves or with help from their families.

The conversion score of each part of the SF-36 was calculated from the actual score using the following formula (23): Conversion score $=($ Actual score-Probable lowest score)/Probable highest score-Probable lowest score) x $100 \%$.

A higher conversion score indicated a better QoL. The total QoL score was the sum of the scores for each section of the questionnaire.

Statistical analysis. Statistical analysis was performed using SPSS 22.0 for Windows (IBM Corp.). Continuous variables were expressed as the mean \pm standard deviation and comparison between groups was performed using Student's t-test. Categorical variables were expressed as absolute numbers and comparison between groups was performed using Fisher's exact test. $\mathrm{P}<0.05$ was considered to indicate a statistically significant difference.

\section{Results}

Baseline characteristics. During the enrollment period, 109 patients with IPN were admitted to Jinling Hospital. Of these, 101 patients were included in the present study and 8 were excluded. Among the 8 excluded cases, 6 patients (5.9\% of all patients) died during hospitalization or after being discharged from hospital, including 3 who succumbed to septic shock, 2 who died from major bleeding and 1 from unknown causes. Among the patients included, 40 (39.6\%) were treated with ON and $61(60.4 \%)$ with MID. There were 66 males and 35 females with a median age of 46 years (interquartile range, 41.5-56.0).

There was no difference between the two groups in terms of age, gender, drinking history, pancreatic necrosis area, positive blood culture, recurrent pancreatitis and the time from discharge to follow-up (Table I). The duration of stay at the ICU in the ON group was longer than that in the MID group (20.28 \pm 3.32 vs. $10.36 \pm 2.21, \mathrm{P}=0.002$; Fig. 1). Patients in the MID group required more MID procedures than those in the ON group ( $\mathrm{P}=0.005$; Fig. 2). The BMI after discharge was significantly higher in the MID than in the ON group (21.25 \pm 3.60 vs. $19.26 \pm 2.42, \mathrm{P}=0.003$; Fig. 3$)$. The incidence of whole pancreatic loss was significantly higher in the ON group (28 vs. 17, $\mathrm{P}<0.001$ ). The diet, symptoms of diabetes and the 
Table I. Clinical characteristics of the patients in the MID group and ON group during their hospital stay.

\begin{tabular}{|c|c|c|c|}
\hline Variables & MID $(n=61)$ & $\mathrm{ON}(\mathrm{n}=40)$ & P-value \\
\hline Age (years) & $49.16 \pm 1.74$ & $48.65 \pm 1.87$ & 0.845 \\
\hline Sex & & & 0.953 \\
\hline Male & 40 & 26 & \\
\hline Female & 21 & 14 & \\
\hline History of drinking & & & 0.485 \\
\hline Present & 24 & 13 & \\
\hline Absent & 37 & 27 & \\
\hline Time interval (months) & $35 \pm 4.74$ & $37 \pm 3.96$ & 0.756 \\
\hline Gallstones & & & 0.244 \\
\hline Present & 45 & 24 & \\
\hline Absent & 16 & 16 & \\
\hline Hypertriglyceridemia & & & 0.161 \\
\hline Present & 11 & 12 & \\
\hline Absent & 50 & 28 & \\
\hline Severity & & & 0.768 \\
\hline Severe & 20 & 12 & \\
\hline Critical & 41 & 28 & \\
\hline APACHE II score & $9.89 \pm 0.80$ & $12.18 \pm 1.06$ & 0.082 \\
\hline Balthazar score & $7.37 \pm 0.26$ & $7.83 \pm 0.28$ & 0.264 \\
\hline Pre-operative infection & & & 0.957 \\
\hline Present & 61 & 40 & \\
\hline Absent & 0 & 0 & \\
\hline BMI $\left(\mathrm{kg} / \mathrm{m}^{2}\right)$ prior to IPN & $27.55 \pm 4.32$ & $27.65 \pm 3.33$ & 0.905 \\
\hline Duration of ICU stay (days) & $10.36 \pm 2.21$ & $20.28 \pm 3.32$ & 0.002 \\
\hline Organ dysfunction & & & 1.000 \\
\hline Present & 40 & 27 & \\
\hline Absent & 21 & 13 & \\
\hline ARDS & & & 0.404 \\
\hline Present & 35 & 27 & \\
\hline Absent & 26 & 13 & \\
\hline AKI & & & 0.839 \\
\hline Present & 28 & 20 & \\
\hline Absent & 33 & 20 & \\
\hline $\mathrm{ACS}$ & & & 0.259 \\
\hline Present & 3 & 5 & \\
\hline Absent & 58 & 38 & \\
\hline \multicolumn{4}{|l|}{ Necrotic area ${ }^{a}$} \\
\hline$<1 / 3$ & 14 & 12 & 0.489 \\
\hline $1 / 3-1 / 2$ & 18 & 7 & 0.239 \\
\hline$>1 / 2$ & 29 & 21 & 0.686 \\
\hline
\end{tabular}

${ }^{a}$ Necrotic area was judged by experienced radiologists based on radiological characteristics of necrosis according to the contrast-enhanced CT images. ON, open necrosectomy; MID, minimally invasive drainage; BMI, body mass index; IPN, infected pancreatitis necrosis; ARDS, acute respiratory distress syndrome; APACHE, Acute Physiology and Chronic Health Evaluation; AKI, acute kidney injury; ACS, abdominal compartment syndrome; time interval, time from discharge to follow-up. Severe acute pancreatitis is defined by the presence of either infected (peri) pancreatic necrosis or persistent organ failure. Critical acute pancreatitis is defined by the presence of infected (peri) pancreatic necrosis and persistent organ failure.

prevalence of pseudocyst and intestinal fistula at the follow-up were similar between the two groups (Table II).
Exocrine and endocrine pancreatic function and QoL. The parameters reflecting the exocrine pancreatic function did 


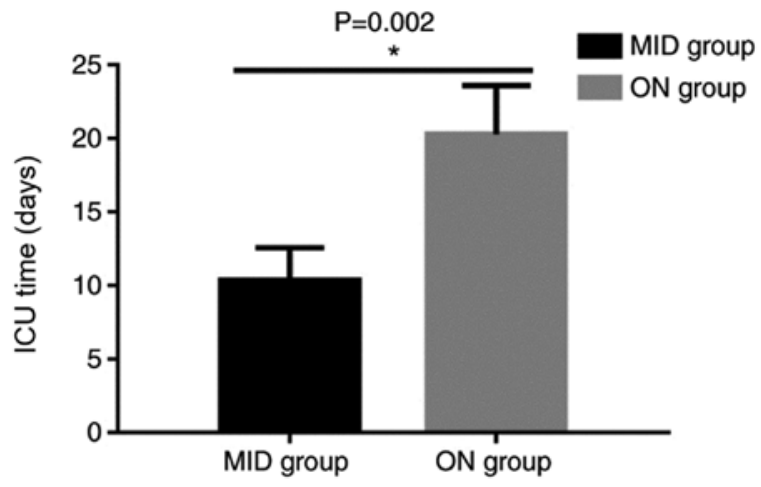

Figure 1. Duration of stay at the ICU compared between the MID and the ON group. ${ }^{*} \mathrm{P}<0.05$. ICU, intensive care unit; $\mathrm{ON}$, open necrosectomy; MID, minimally invasive drainage.

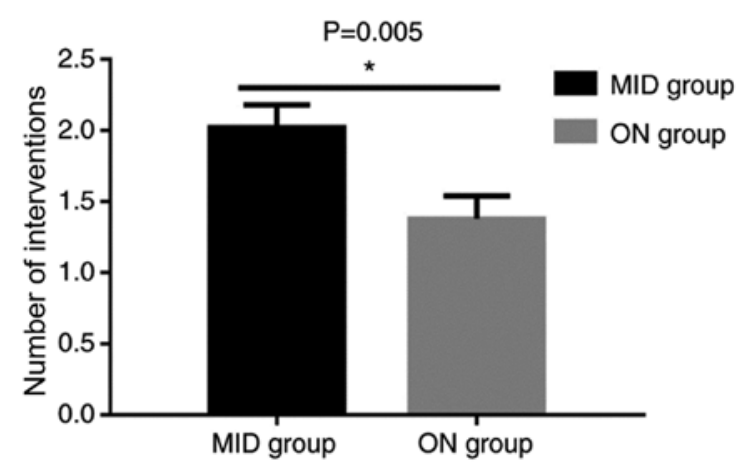

Figure 2. Number of interventions in the MID and the ON group. ${ }^{*} \mathrm{P}<0.05$ $\mathrm{ON}$, open necrosectomy; MID, minimally invasive drainage.

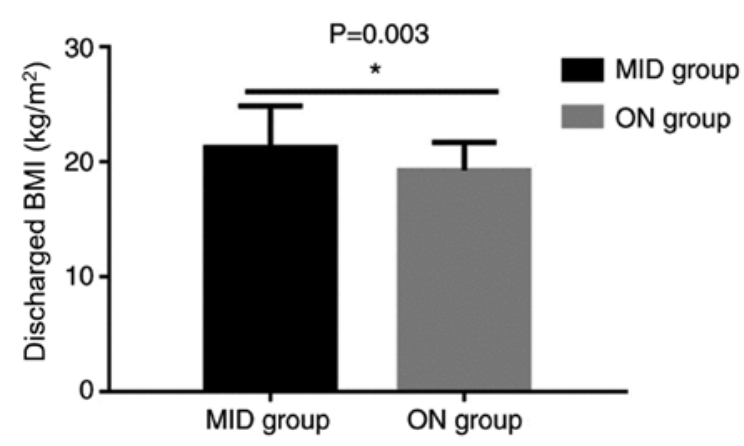

Figure 3. Comparison of BMI at discharge in the MID and the ON group. ${ }^{*} \mathrm{P}<0.05$. ON, open necrosectomy; MID, minimally invasive drainage; BMI, body mass index.

not differ significantly between the MID and ON groups. Specifically, the incidence of diarrhea (12/61 vs. 4/40), abdominal pain (6/61 vs. 3/40), abdominal distention (6/61 vs. 5/40), exogenous trypsin intake (19/61 vs. 10/40) and FE-1 concentration $(264.03 \pm 22.88$ vs. $245.74 \pm 30.68 \mu \mathrm{g} / \mathrm{g})$ in the two groups was comparable (Table III). In addition, no statistically significant difference in endocrine pancreatic function (FBG, FINS, fasting C-peptide, HbA1c, 2-h PG, 2-h insulin and 2-h C-peptide) was observed between the two groups (Table IV).

As outlined in Table $\mathrm{V}$ and Fig. 4, the results of the assessment with the QoL questionnaire indicated significant
Table II. Clinical characteristics of the patients in the MID group and ON group during the follow-up time.

\begin{tabular}{|c|c|c|c|}
\hline Variable & $\operatorname{MID}(n=61)$ & $\mathrm{ON}(\mathrm{n}=40)$ & P-value \\
\hline \multicolumn{4}{|c|}{$\begin{array}{l}\text { Physical activity level } \\
\text { based on walking } \\
\text { distance }(\mathrm{km} / \text { day })\end{array}$} \\
\hline$<3$ & 25 & 14 & 0.546 \\
\hline $3-5$ & 10 & 11 & 0.179 \\
\hline $5-10$ & 10 & 5 & 0.590 \\
\hline$>10$ & 3 & 4 & 0.430 \\
\hline None & 13 & 6 & 0.604 \\
\hline BMI (kg/m²) & $21.25 \pm 3.60$ & $19.26 \pm 2.42$ & 0.003 \\
\hline Reduced oil diet & & & 0.801 \\
\hline Present & 50 & 32 & \\
\hline Absent & 11 & 8 & \\
\hline Diabetes symptoms & & & 1.000 \\
\hline Present & 10 & 7 & \\
\hline Absent & 51 & 33 & \\
\hline Insulin use & & & 0.709 \\
\hline Present & 4 & 4 & \\
\hline Absent & 57 & 36 & \\
\hline Loss of pancreas ${ }^{\mathrm{a}}$ & & & $<0.001$ \\
\hline Present & 17 & 28 & \\
\hline Absent & 44 & 12 & \\
\hline Pseudocyst & & & 0.673 \\
\hline Present & 3 & 3 & \\
\hline Absent & 58 & 37 & \\
\hline Intestinal fistula & & & 0.430 \\
\hline Present & 3 & 4 & \\
\hline Absent & 58 & 36 & \\
\hline
\end{tabular}

${ }^{a}$ Loss of whole pancreas was determined by careful comparison of the CT images prior to and after the interventions. ON, open necrosectomy; MID, minimally invasive drainage. These clinical characteristics were determined at the end of the follow-up time.

differences between the two groups in terms of general health perception $(19.39 \pm 3.07$ vs. $17.37 \pm 3.63, \mathrm{P}=0.003$; Fig. $4 \mathrm{~A})$, vitality $(18.93 \pm 2.88$ vs. $17.57 \pm 3.47, \mathrm{P}=0.035$; Fig. $4 \mathrm{~B})$, social role functioning $(8.85 \pm 1.43$ vs. $8.15 \pm 1.98, \mathrm{P}=0.042$; Fig. $4 \mathrm{C})$, emotional role functioning $(5.33 \pm 1.07$ vs. $4.82 \pm 1.25, \mathrm{P}=0.034$; Fig. 4D), mental health $(24.21 \pm 3.31$ vs. $22.57 \pm 3.91, P=0.026$; Fig. 4E) and total QoL score $(125.12 \pm 13.16$ vs. 116.50 \pm 16.94 , $\mathrm{P}=0.005$; Fig. 4F). However, physical functioning $(26.77 \pm 3.29$ vs. $25.75 \pm 4.04, \mathrm{P}=0.168)$, physical role functioning $(6.77 \pm 1.67$ vs. $6.20 \pm 1.69, \mathrm{P}=0.099)$ and bodily pain $(10.78 \pm 1.46$ vs. $10.60 \pm 1.52, \mathrm{P}=0.556)$ did not differ significantly between the MID and ON groups.

\section{Discussion}

Several studies indicated that MID is the preferred method for the treatment of IPN. The present study demonstrated 
Table III. Comparison of pancreatic exocrine function between patients in MID group and ON group.

\begin{tabular}{lccc}
\hline Variable & MID (n=61) & ON (n=40) & P-value \\
\hline Diarrhea & & & 0.268 \\
Present & 12 & 36 & \\
Absent & 49 & & 1.000 \\
Abodominal pain & & 3 & \\
Present & 6 & 37 & \\
Absent & 55 & & 0.749 \\
Abdominal distention & & 5 & \\
Present & 6 & 35 & \\
Absent & 55 & & 0.968 \\
FE-1 $(\mu \mathrm{g} / \mathrm{g})$ & & 8 & \\
$<200$ & 12 & 32 & \\
$\geq 200$ & 49 & & \\
Mean & $264.03 \pm 22.88$ & $245.74 \pm 30.68$ & 0.656 \\
Exogenous trypsin & & & 0.653 \\
intake & & & \\
Present & 19 & 30 & \\
Absent & 42 & & \\
\hline
\end{tabular}

ON, open necrosectomy; MID, minimally invasive drainage; FE-1, fecal elastase-1.

Table IV. Comparison of pancreatic endocrine function between patients in MID group and ON group.

\begin{tabular}{lrrr}
\hline Variable & MID (n=61) & ON (n=40) & P-value \\
\hline FBG & $5.95 \pm 1.44$ & $6.91 \pm 2.85$ & 0.055 \\
HBA1c (\%) & $5.96 \pm 1.04$ & $6.49 \pm 1.88$ & 0.073 \\
FINS & $7.24 \pm 0.81$ & $9.98 \pm 1.83$ & 0.130 \\
Fasting C-peptide & $1.41 \pm 0.70$ & $2.07 \pm 0.55$ & 0.160 \\
2-h insulin & $34.03 \pm 3.32$ & $43.40 \pm 7.25$ & 0.194 \\
2-h C-reactive peptide & $5.21 \pm 0.38$ & $5.33 \pm 0.53$ & 0.859 \\
2-h PG & $11.54 \pm 8.09$ & $11.98 \pm 6.61$ & 0.777 \\
\hline
\end{tabular}

ON, open necrosectomy; MID, minimally invasive drainage; FBG, fasting blood glucose; HBA1c, glycated hemoglobin; FINS, free insulin; PG, plasma glucose.

that the patients in the MID group had a higher BMI at the follow-up than those in the ON group, while no significant difference was present prior to the intervention. This result indicates that MID is able to affect metabolism and nutrition. ON thoroughly removes necrotic tissue but may lead to loss of pancreatic tissue. The time spent at the ICU by patients subjected to $\mathrm{ON}$ was longer than that of patients who received MID $(\mathrm{P}<0.05)$. However, it cannot be determined whether MID is directly able to reduce the time at the ICU, since the patients treated with $\mathrm{ON}$ had typically more severe IPN or organ failure, requiring treatment for a longer duration. Furthermore, patients subjected to MID required an
Table V. Comparison of QoL between patients in the MID group and $\mathrm{ON}$ group.

\begin{tabular}{lrrr}
\hline Item & MID $(\mathrm{n}=61)$ & ON $(\mathrm{n}=40)$ & P-value \\
\hline Physical functioning & $26.77 \pm 3.29$ & $25.75 \pm 4.04$ & 0.168 \\
Physical role & $6.77 \pm 1.67$ & $6.20 \pm 1.69$ & 0.099 \\
functioning & & & \\
Bodily pain & $10.78 \pm 1.46$ & $10.60 \pm 1.52$ & 0.556 \\
General health & $19.39 \pm 3.07$ & $17.37 \pm 3.63$ & 0.003 \\
perception & & & \\
Vitality & $18.93 \pm 2.88$ & $17.57 \pm 3.47$ & 0.035 \\
Social role functioning & $8.85 \pm 1.43$ & $8.15 \pm 1.98$ & 0.042 \\
Emotional role & $5.33 \pm 1.07$ & $4.82 \pm 1.25$ & 0.034 \\
functioning & & & \\
Mental health & $24.21 \pm 3.31$ & $22.57 \pm 3.91$ & 0.026 \\
Total QoL score & $125.12 \pm 13.16$ & $116.50 \pm 16.94$ & 0.005 \\
\hline
\end{tabular}

ON, open necrosectomy; MID, minimally invasive drainage; QoL, quality of life.

increased frequency of MID procedures than the patients in the ON group. Patients with AP may develop prediabetes and/or DM after being discharged from hospital (24). Impairment of the endocrine function of the pancreas after AP is associated with a decreased level of plasma insulin after fasting glucose stimulus and it occurs more frequently in patients recovering from severe AP (SAP) (25). The pancreas is a key organ in glucose homeostasis and the development of DM as a result of pancreatic necrosis after AP has been reported (26). Although numerous studies demonstrated that AP, and SAP in particular, may impair pancreatic endocrine function (12), there was no significant difference in this function between the MID and ON groups of the present study. As documented in a previous study by our group, the extent of pancreatic necrosis, wall of necrosis and insulin resistance are independent risk factors for new-onset DM after AP (27), and this risk is increased in patients with simultaneous pancreatic necrosis and persistent organ failure (28). Thus, pancreatic necrosis may have a critical role in the impairment of pancreatic endocrine function. The interventional methods to remove the necrotic tissue have a limited effect on diabetes after AP. There was also no significant difference in the exocrine function of the pancreas between the MID and $\mathrm{ON}$ groups of patients.

Several studies verified the validity and reliability of the SF-36 questionnaire for the evaluation of QoL (29-35). The physical functioning aspect of the QoL questionnaire was improved during the first year of recovery from the acute necrotizing pancreatitis (36). The total QoL score among patients with SAP after five years was comparable to that of the normal population (37). Numerous complications after IPN, including incisional hernia, gastrointestinal fistulas, intra-abdominal bleeding and diabetes, affected the QoL. Certain patients in the MID group required repeated acupuncture and placement of multiple drainage tubes, which may make them feel less comfortable than patients undergoing ON. The present study did not identify any 

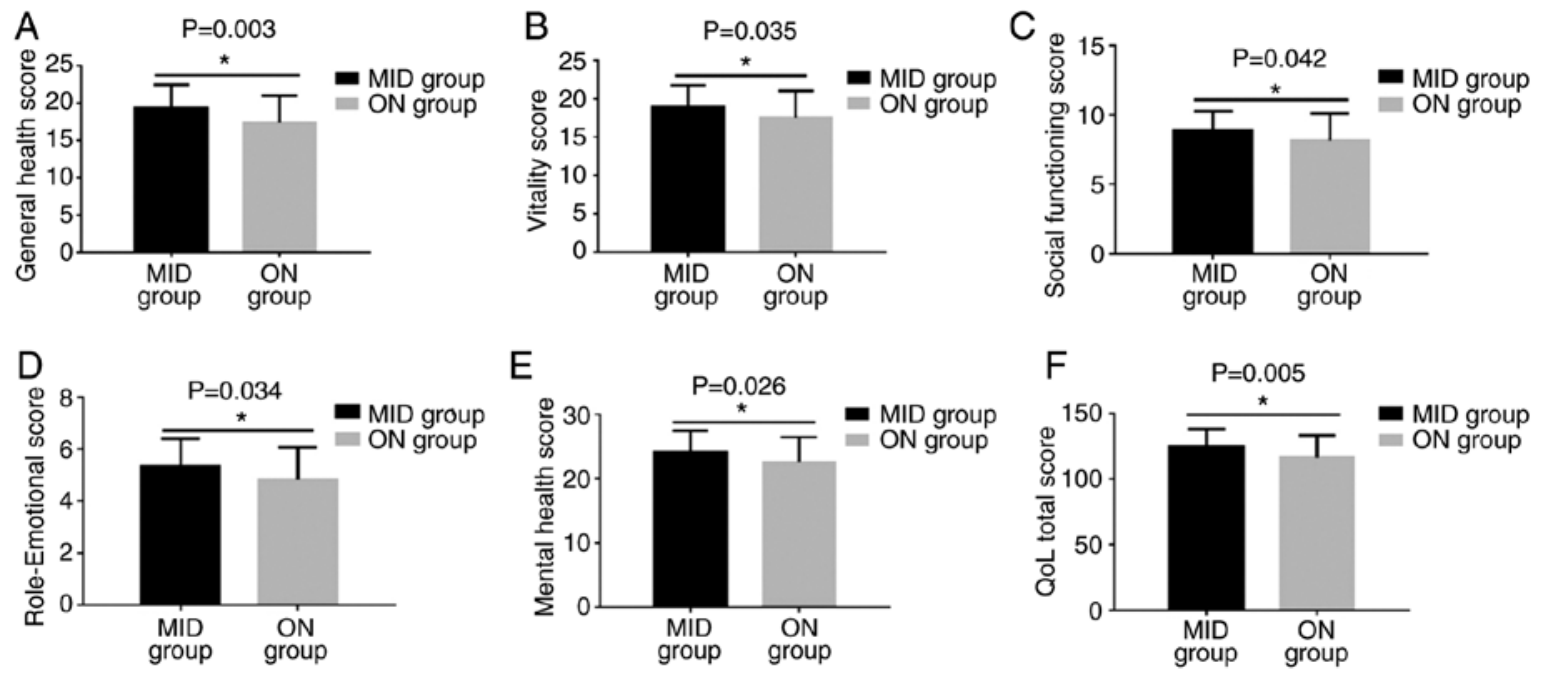

Figure 4. Results of the Short Form 36-item questionnaire for QoL compared between the two groups. (A) General health score, (B) vitality score, (C) social functioning score, (D) role-emotional score, (E) mental health score, (F) QoL total score. " $\mathrm{P}<0.05$. ON, open necrosectomy; MID, minimally invasive drainage; QoL, quality of life.

significant differences in physical functioning, physical role functioning and bodily pain between the two groups. However, MID provided a significant benefit over ON in terms of general health, vitality, social functioning, emotional role functioning and mental health. It is worth mentioning that it is not possible to exclude the possibility that these differences are derived from a difference in initial disease severity between groups. These results indicate that although MID and ON have a similar impact on physical indices, they have a different impact on mental and social indices. This is probably due to the fact that patients that underwent MID had a better QoL post-surgery. MID resulted in better general health, vitality and mental health as compared with ON. The reason for this difference may be the fact that patients treated with ON suffered from the abdominal incision, reduced BMI and severe pancreatic complications. These complications obviously affected their mental and social functioning. Accordingly, patients in the MID group had higher total QoL scores than patients undergoing $\mathrm{ON}$.

The major limitation of the present study is its retrospective design. A prospective randomized controlled study will be necessary to determine the advantages and disadvantages of ON and MID for patients with IPN. Another limitation is that the sample size of the present study is relatively small. Future studies including a larger number of patients are required. Furthermore, the present study was a single-center study. A multi-center study or a meta-analysis including data from more centers will provide more convincing conclusions in the future.

In conclusion, the present study demonstrated that patients with IPN who received MID achieved a better QoL than those treated with ON. However, the endocrine and exocrine functions of the pancreas were similar in the two groups.

\section{Acknowledgements}

Not applicable.

\section{Funding}

The present study was supported by grants from the Natural Science Foundation of Zhejiang Province, China (grant no. LY18H150005), The Science and Technology Foundation of Zhejiang Province, China (grant no. 2013C37022), The Key Research and Development Program Foundation of Jiangsu Province of China (grant no. BE2016749) and The National Natural Science Foundation of China (grant nos. 81670588 and 81570584).

\section{Availability of data and materials}

The datasets used and/or analyzed during the current study are available from the corresponding author on reasonable request.

\section{Authors' contributions}

JT, JL, QX, and JZ designed the study. YY, QX, LK, ZT and WL collected the data and performed statistical analysis. QX, WL and JT wrote the manuscript. All authors read and reviewed the final version of the manuscript.

\section{Ethics approval and consent to participate}

The experimental protocol was approved by the Ethics Committee of the Jinling Hospital (Nanjing, China). Written informed consent was obtained from all patients.

\section{Patient consent for publication}

Written informed consent regarding the publication of clinical data was obtained from every patient enrolled in this study.

\section{Competing interests}

The authors declare that they have no competing interests. 


\section{References}

1. Banks PA, Bollen TL, Dervenis C, Gooszen HG, Johnson CD, Sarr MG, Tsiotos GG and Vege SS; Acute Pancreatitis Classification Working Group: Classification of acute pancreatitis-2012: Revision of the Atlanta classification and definitions by international consensus. Gut 62: 102-111, 2013.

2. Besselink MG, van Santvoort HC, Boermeester MA, Nieuwenhuijs VB, van Goor $\mathrm{H}$, Dejong $\mathrm{CH}$, Schaapherder AF and Gooszen HG; Dutch Acute Pancreatitis Study Group: Timing and impact of infections in acute pancreatitis. Br J Surg 96 : 267-273, 2009

3. Banks PA and Freeman ML; Practice Parameters Committee of the American College of Gastroenterology: Practice guidelines in acute pancreatitis. Am J Gastroenterol 101: 2379-2400, 2006.

4. Working Group IAP/APA Acute Pancreatitis Guidelines: IAP/APA evidence-based guidelines for the management of acute pancreatitis. Pancreatology 13 (Suppl 2): e1-e15, 2013.

5. Working Party of the British Society of Gastroenterology; Association of Surgeons of Great Britain and Ireland; Pancreatic Society of Great Britain and Ireland; Association of Upper GI Surgeons of Great Britain and Ireland: UK guidelines for the management of acute pancreatitis. Gut 54 (Suppl 3): iiil-iii9, 2005

6. Traverso LW and Kozarek RA: Pancreatic necrosectomy: Definitions and technique. J Gastrointest Surg 9: 436-439, 2005.

7. Werner J, Feuerbach S, Uhl W and Büchler MW: Management of acute pancreatitis: From surgery to interventional intensive care. Gut 54: 426-436, 2005

8. Babu RY, Gupta R, Kang M, Bhasin DK, Rana SS and Singh R: Predictors of surgery in patients with severe acute pancreatitis managed by the step-up approach. Ann Surg 257: 737-750, 2013.

9. Carter CR, McKay CJ and Imrie CW: Percutaneous necrosectomy and sinus tract endoscopy in the management of infected pancreatic necrosis: An initial experience. Ann Surg 232: $175-180,2000$.

10. van Santvoort HC, Besselink MG, Bakker OJ, Hofker HS Boermeester MA, Dejong CH, van Goor H, Schaapherder AF, van Eijck $\mathrm{CH}$, Bollen TL, et al: A step-up approach or open necrosectomy for necrotizing pancreatitis. N Engl J Med 362: 1491-1502, 2010.

11. Parikh PY, Pitt HA, Kilbane M, Howard TJ, Nakeeb A, Schmidt CM, Lillemoe KD and Zyromski NJ: Pancreatic necrosectomy: North American mortality is much lower than expected. J Am Coll Surg 209: 712-719, 2009.

12. Liu L, Yan H, Liu W, Cui J, Wang T, Dai R, Liang H, Luo H and Tang L: Abdominal paracentesis drainage does not increase infection in severe acute pancreatitis: A prospective study. J Clin Gastroenterol 49: 757-763, 2015.

13. Ai X, Qian X, Pan W, Xu J,Hu W, Terai T, Sato N and Watanabe S: Ultrasound-guided percutaneous drainage may decrease the mortality of severe acute pancreatitis. J Gastroenterol 45: 77-85, 2010.

14. Greenberg JA, Hsu J, Bawazeer M, Marshall J, Friedrich JO, Nathens A, Coburn N, May GR, Pearsall E and McLeod RS: Clinical practice guideline: Management of acute pancreatitis. Can J Surg 59: 128-140, 2016.

15. Bozkurt T, Maroske D and Adler G: Exocrine pancreatic function after recovery from necrotizing pancreatitis Hepatogastroenterology 42: 55-58, 1995.

16. Ibars EP, Sánchez de Rojas EA, Quereda LA, Ramis RF, Sanjuan VM and Peris RT: Pancreatic function after acute biliary pancreatitis: Does it change? World J Surg 26: 479-486, 2002.

17. Appelros S, Lindgren S and Borgström A: Short and long term outcome of severe acute pancreatitis. Eur J Surg 167: 281-286, 2001

18. Tong Z, Ke L, Li B, Li G, Zhou J, Shen X, Li W, Li N and Li J: Negative pressure irrigation and endoscopic necrosectomy through man-made sinus tract in infected necrotizing pancreatitis: A technical report. BMC Surg 16: 73, 2016.

19. Rämö JT, Kaye SM, Jukarainen S, Bogl LH, Hakkarainen A, Lundbom J, Lundbom N, Rissanen A, Kaprio J, Matikainen N and Pietiläinen KH: Liver fat and insulin sensitivity define metabolite profiles during a glucose tolerance test in young adult twins. J Clin Endocrinol Metab 102: 220-231, 2017.

20. Dominici R and Franzini C: Fecal elastase-1 as a test for pancreatic function: A review. Clin Chem Lab Med 40: 325-332, 2002.
21. Martínez J, Laveda R, Trigo C, Frasquet J, Palazón JM and Pérez-Mateo M: Fecal elastase-1 determination in the diagnosis of chronic pancreatitis. Gastroenterol Hepatol 25: 377-382, 2002 (In Spanish).

22. Adorno ML and Brasil-Neto JP: Assessment of the quality of life through the SF-36 questionnaire in patients with chronic nonspecific low back pain. Acta Ortop Bras 21: 202-207, 2013.

23. Bagheri Z, Jafari P, Mahmoodi M and Dabbaghmanesh MH: Testing whether patients with diabetes and healthy people perceive the meaning of the items in the Persian version of the SF-36 questionnaire similarly: A differential item functioning analysis. Qual Life Res 26: 835-845, 2017.

24. Das SL, Singh PP, Phillips AR, Murphy R, Windsor JA and Petrov MS: Newly diagnosed diabetes mellitus after acute pancreatitis: A systematic review and meta-analysis. Gut 63: 818-831, 2014.

25. Malecka-Panas E, Gasiorowska A, Kropiwnicka A,Zlobinska A and Drzewoski J: Endocrine pancreatic function in patients after acute pancreatitis. Hepatogastroenterology 49: 1707-1712, 2002.

26. Tim LO and Segal I: Exocrine pancreatic function in patients with idiopathic necrosis of the femoral head. S Afr Med J 54: 441-442, 1978.

27. Tu J,Zhang J, Ke L, Yang Y, Yang Q, Lu G, Li B, Tong Z, Li W and $\mathrm{Li} \mathrm{J}$ : Endocrine and exocrine pancreatic insufficiency after acute pancreatitis: Long-term follow-up study. BMC Gastroenterol 17: 114, 2017.

28. Tu J, Yang Y, Zhang J, Yang Q, Lu G, Li B, Tong Z, Ke L, Li W and Li J: Effect of the disease severity on the risk of developing new-onset diabetes after acute pancreatitis. Medicine (Baltimore) 97: e10713, 2018

29. Donnally CJ III, Gupta A, Bensalah K, Tuncel A, Raman J, Pearle MS and Lotan Y: Longitudinal evaluation of the SF-36 quality of life questionnaire in patients with kidney stones. Urol Res 39: 141-146, 2011.

30. Fujio S, Arimura H,Hirano H,Habu M, Bohara M, Moinuddin FM, Kinoshita Y and Arita K: Changes in quality of life in patients with acromegaly after surgical remission-A prospective study using SF-36 questionnaire. Endocr J 64: 27-38, 2017.

31. Gardikiotis I, Manole A and Azoicăi D: Quality of life with mastectomy for breast cancer, in terms of patients' responses of SF-36 questionnaire. Rev Med Chir Soc Med Nat Iasi 119: 529-535, 2015.

32. Iudici M,Cuomo G, Vettori S, Avellino M and Valentini G: Quality of life as measured by the short-form 36 (SF-36) questionnaire in patients with early systemic sclerosis and undifferentiated connective tissue disease. Health Qual Life Outcomes 11: 23, 2013.

33. López-Pérez P, Miranda-Novales G, Segura-Méndez NH, Del Rivero-Hernández L, Cambray-Gutiérrez $C$ and Chávez-García A: Study of quality of life in adults with common variable immunodeficiency by using the questionnaire SF-36. Rev Alerg Mex 61: 52-58, 2014 (In Spanish).

34. Shu J, Lo S, Phillips M, Sun F, Seldin DC, Berenbaum I, Berk JL and Sanchorawala V: Depression and anxiety in patients with AL amyloidosis as assessed by the SF-36 questionnaire: Experience in 1226 patients. Amyloid 23: 188-193, 2016.

35. Pezzilli R, Morselli-Labate AM, Frulloni L, Cavestro GM, Ferri B, Comparato G, Gullo L and Corinaldesi R: The quality of life in patients with chronic pancreatitis evaluated using the SF-12 questionnaire: A comparative study with the SF-36 questionnaire. Dig Liver Dis 38: 109-115, 2006.

36. Wright SE, Lochan R, Imrie K, Baker C, Nesbitt ID, Kilner AJ and Charnley RM: Quality of life and functional outcome at 3 , 6 and 12 months after acute necrotising pancreatitis. Intensive Care Med 35: 1974-1978, 2009.

37. Halonen KI, Pettilä V, Leppäniemi AK, Kemppainen EA, Puolakkainen PA and Haapiainen RK: Long-term health-related quality of life in survivors of severe acute pancreatitis. Intensive Care Med 29: 782-786, 2003.

This work is licensed under a Creative Commons Attribution-NonCommercial-NoDerivatives 4.0 International (CC BY-NC-ND 4.0) License. 